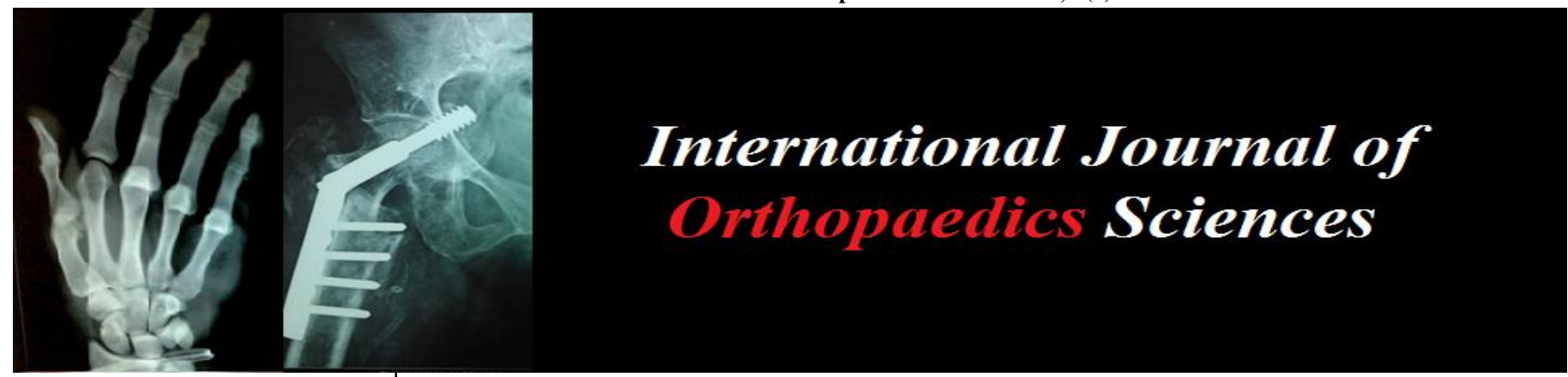

E-ISSN: 2395-1958

P-ISSN: 2706-6630

IJOS 2020; 6(3): 476-479

(C) 2020 IJOS

www.orthopaper.com

Received: 04-05-2020

Accepted: 06-06-2020

Dr. Rajesh K Ambulgekar Proff and Hod, Deptt. of Orthopaedics, Dr. Shankarrao Chavan Government Medical College, Nanded, Maharashtra, India

Dr. Vishal Gurnan

Resident Deptt. of Orthopaedics, Dr. Shankarrao Chavan Government Medical College, Nanded, Maharashtra, India
Corresponding Author: Dr. Vishal Gurnani Resident Deptt. of Orthopaedics, Dr. Shankarrao Chavan Government Medical College, Nanded, Maharashtra, India

\section{Evaluate clinical outcome of open reduction and internal fixation with volar locking plates for displaced unstable distal end radius fractures}

\author{
Dr. Rajesh K Ambulgekar and Dr. Vishal Gurnani
}

DOI: https://doi.org/10.22271/ortho.2020.v6.i3h.2239

Abstract

Background: Fracture of distal radius usually occur as a result of high energy trauma in younger individual with good bone density and also reported in elderly osteoporotic bone. The management is done by cast immobilization to various operative modalities percutaneous $\mathrm{K}$ - wire fixation to provide good to excellent results. This study was done to determine the clinical outcome of displaced unstable distal end radius fracture treated with volar locking plates.

Objectives: 1 . To study the demographic factors of patients with displaced unstable distal end radius fracture. 2. To determine the clinical outcome of patients who treated with volar locking plates.

Materials and Methods: This is a prospective observational study done on 33 patients with distal end of radius fracture. The detailed history of the patient was taken and radiographs were assessed. The data was quantified by Modified Gartland and Werley score in which outcome was evaluated. Patient was discharged on $12^{\text {th }}$ postoperative day and followed up after 1st, 2nd, 3rd, 6thmonth and then yearly.

Results: In the present study, $63.63 \%$ cases from were from the age group 20-34 years, we had 29 cases $(87.88 \%)$ males. Most common mode of injury was road traffic accident, in 18 cases $(54.55 \%)$. In the present study, as per Frykman type VIII type of fracture was the commonest with 21 cases (63.64\%). Ulnar was 25 degrees and radial were 15.60. An equal grip strength of the affected as the normal was noted in 27 cases $(81.82 \%)$. At the final analysis of the outcome of our study excellent results were noted in 15 cases $45.45 \%$.

Conclusions: Fracture of distal end of radius is one of the commonest fractures. This fracture is more common in males $(87.8 \%)$ with predominance on right side. Road traffic accident is still the common mode of injury than fall. On follow up excellent functional outcome found in $45.45 . \%$ cases with $81.82 \%$ patients achieved good grip strength.

Keywords: Open reduction, internal fixation, volar locking plates, distal end radius fractures

\section{Introduction}

Fracture of distal end of radius is one of the common fractures due to trauma and self-fall accounting for more than $20 \%$ of all fractures seen in the casualty department. ${ }^{1}$ Fracture of distal radius usually occur as a result of high energy trauma in younger individual with good bone density and are associated with substantial articular and periarticular tissue injury and also reported in elderly osteoporotic bone ${ }^{[2]}$.

The management of distal end radius has been changed dramatically over the previous initial methods like cast immobilization to various operative modalities percutaneous $\mathrm{K}$ - wire fixation, External fixation (ligamentotaxis), K- wire fixation plus External fixation, Internal fixation with volar and dorsal plates. All above mentioned methods provide good to excellent results ${ }^{[3-6]}$.

This study was done to determine the clinical outcome of displaced unstable distal end radius fracture treated with volar locking plates.

\section{Aims and Objectives}

1. To study the demographic factors of patients with displaced unstable distal end radius fracture.

2. To determine the clinical outcome of patients who treated with volar locking plates. 


\section{Materials and Methods}

This is a prospective observational study. After obtaining approval from the Institutional ethics committee, 33 patients with distal end of radius fracture admitted in male and female orthopedic wards, in a tertiary care center were taken in the study. The detailed history of the patient was taken regarding personal data history, mode of injury, pre- injury ambulatory status, preexisting local and systemic condition that may affect recovery. Full clinical examination was done to assess the general condition of the neighboring joints and any associated injuries. Patients with open fractures, fractures due to malignancy, stable fractures were excluded. The radiographs were assessed in terms of loss of radial inclination, loss of palmar tilt, or presence of dorsal tilt, radial shortening fractures would be classified according to Frykman classification and AO classification of findings on dead lateral and anteroposterior radiographs.

The data was quantified by Modified Gartland and Werley score in which outcome was evaluated by clinical measures that included Flexion, Extension, Pronation, Supination, Percentage Grip and Power The dressing was done on postoperative $12^{\text {th }}$ day. Patient was discharged on $12^{\text {th }}$ postoperative day and followed up after 1st, 2nd, 3rd, 6thmonth and then yearly. Functional evaluation of the patients was done according to the Demerit point system of Gartland and Werley with Sarmiento et al. modification. All the relevant data was entered in pre tested case record form. The data was analyzed by using Microsoft Excel. Results on continuous measurements are presented on Mean \pm SD (MinMax) and results on categorical measurements are presented in Number. (\%)

\section{Results}

In the present study, 11 cases $(33.33 \%)$ were from the age group 20-30 years, 10 cases $(30.30 \%)$ cases were from the age group 31-40 years, in 41-50 years age group we had 6 cases $(18.18 \%)$ and in 51-60 years age group, we had 5 cases $(15.15 \%)$. Only 1 case $(3.03 \%)$ was from > 60 years age group. In the study males outnumbered the females that male to female ratio was $6.75: 1$. we had 4 cases $(12.12 \%)$ females and 29 cases $(87.88 \%)$ males.

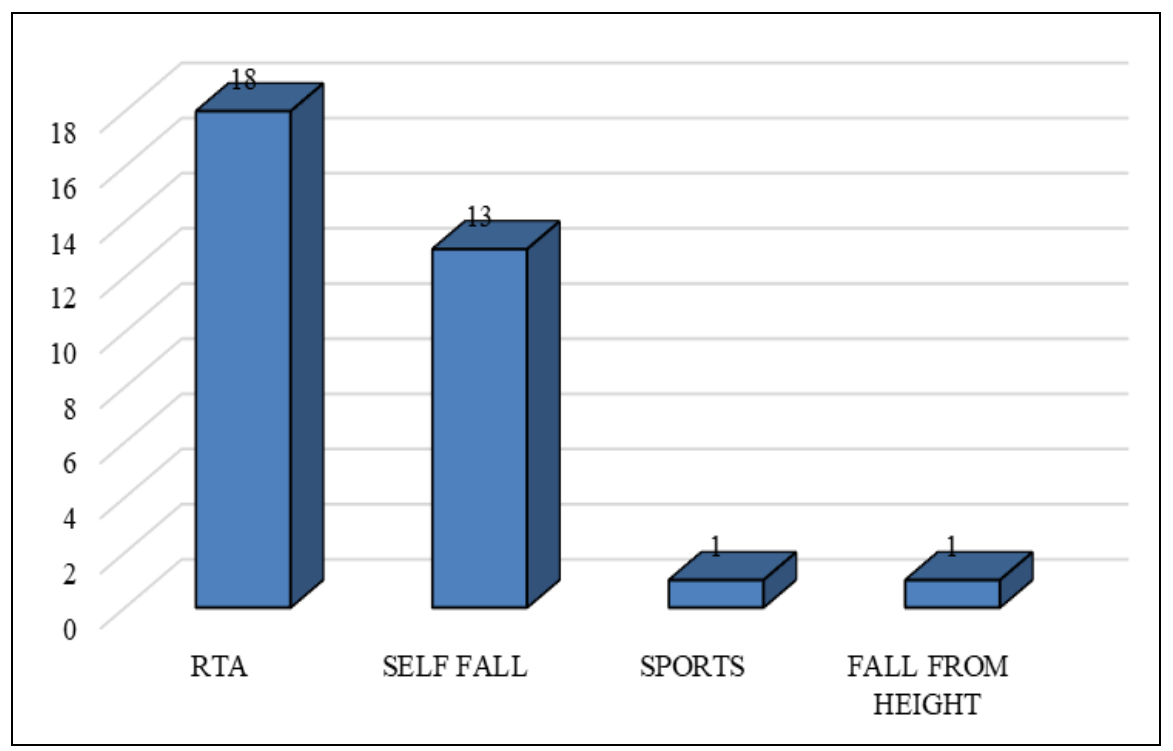

Fig 1: Distribution of study subjects according to the cause of injury

In the study as per the mode of injury evaluated, we had 18 cases $(54.55 \%)$ were as a result of road traffic accident, 13 cases $(39.39 \%)$ were due to self-fall, sports and fall from tree were responsible for 3.03 cases each (Figure 1)

Table 1: Type of Fracture - According to Frykman and AO Classification

\begin{tabular}{|c|c|c|c|c|c|}
\hline Type of Fracture & Frequency & Percent & A-O Type & Frequency & Percent \\
\hline III & 1 & $3.03 \%$ & B3 & 9 & $27.27 \%$ \\
\hline IV & 1 & $3.03 \%$ & C 1 & 1 & $3.03 \%$ \\
\hline VI & 7 & $21.21 \%$ & C 2 & 8 & $24.24 \%$ \\
\hline VII & 3 & $9.09 \%$ & C 3 & 13 & $39.39 \%$ \\
\hline VIII & 21 & $63.64 \%$ & & & \\
\hline
\end{tabular}

In the present study, as per Frykman type VIII type of fracture was the commonest with 21 cases (63.64\%) followed by VI type of fracture 7 cases $(21.21 \%)$, VII type of fracture 3 cases
$(9.09 \%)$, III and IV with 1 case $(3.03 \%)$. As per AO type , C3 type of fracture was the commonest with 13 cases $(39.39 \%)$. (Table 1)

Table 2: Assessment of range of Movements

\begin{tabular}{|c|c|c|c|c|c|c|}
\hline Parameters & Radial & Ulnar & Pronation & Supination & Palmar & Dorsal \\
\hline Mean & 15.60 & 25 & 70.75 & 77.42 & 60.15 & 60.45 \\
\hline Standard Deviation & 3.98 & 6.37 & 14.09 & 12.63 & 15.63 & 16.02 \\
\hline
\end{tabular}

It was found that while assessing the range of movements, ulnar was 25 degrees, radial was 15.60 ,pronation was 70.75 degrees, supination was 77.42 degrees, palmar flexion was 60.15 degrees and dorsal was 60.45 degrees. (Table 2) 


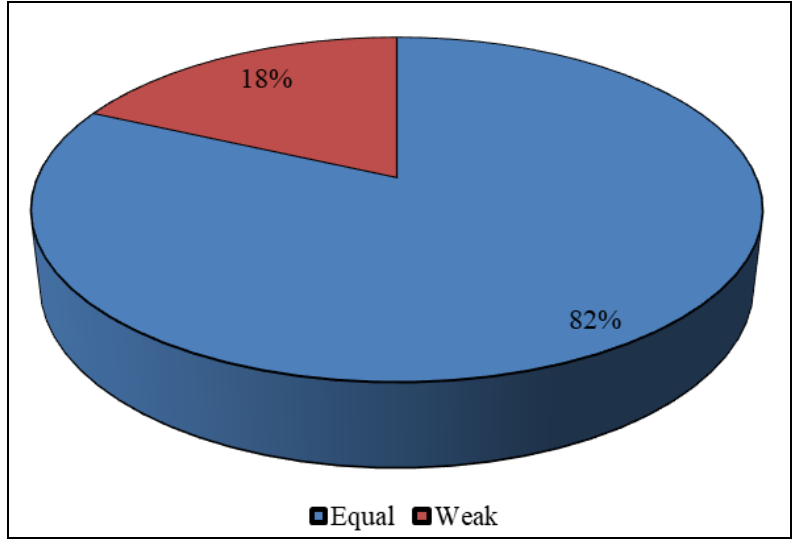

Fig 2: Assessment of the grip strength of affected and non-affected side:

On evaluation of the grip strength of the affected and not affected sides, an equal grip strength of the affected as the normal was noted in 27 cases $(81.82 \%)$ but grip strength of the affected was weaker than normal in 6 cases $(18.18 \%)$. (Figure 3)

Table 3: Score Inherence

\begin{tabular}{|c|c|c|}
\hline Score Inference & Frequency & Percent \\
\hline Excellent & 15 & $45.45 \%$ \\
\hline Fair & 5 & $15.15 \%$ \\
\hline Good & 11 & $33.33 \%$ \\
\hline Poor & 2 & $6.06 \%$ \\
\hline
\end{tabular}

At the final analysis of the outcome of our study excellent results were noted in 15 cases $45.45 \%$, good results were noted in 11 cases $33.33 \%$, fair results were noted in 5 cases $15.15 \%$, poor results were noted in 2 cases $6.06 \%$. (Table 3 )

\section{Discussion}

There is a recent rise in high energy fractures of the distal radius in young adults, because of motor vehicle accidents and recreational activities, which invariably require surgical management Restoration of normal alignment and articular congruity in a displaced fracture can be difficult but is essential for a good functional outcome in terms of early wrist motion, improvement in range of motion and grip strength ${ }^{[7}$, ${ }^{8]}$. It has been shown in the laboratory and clinical studies that extra and intra-articular malunion alters the function of wrist $[7,9,10]$.

In this study males outnumbered the females that male to female ratio was 6.75:1. we had 4 cases $12.12 \%$ females, and 29 cases $87.88 \%$ males. Paritosh Gogna et al. study 23 males and 10 females with an average age of $44.12 \pm 18.63$ years (18-61 years) ${ }^{[11]}$ Sohael M. Khan on 60 patients of distal radius fractures found that Male patients predominated female patients (36 males to24 females) ${ }^{[12]}$ Kavin Khatri et al. ${ }^{[13]}$ on 23 patients found that 16 were males and 7 were female.

In our study In the study as per the mode of injury evaluated we had commonest $54.55 \%$ were as a result of road traffic accident followed by 13 cases $39.39 \%$ were due to self fall, sports and fall from height were responsible for 3.03 cases. Sohael M. Khan et al. ${ }^{[12]}$ reported road traffic accident was the commonest cause of the trauma . Paritosh Gogna et al. ${ }^{[11]}$ reported road traffic accidents was the commonest with $78.78 \%$ (26) cases followed by fall with $21.21 \%$ (7). Kavin khatri et al. reported commonest cause is road traffic accidents with 18 cases followed by fall with 5 cases ${ }^{[13]}$.

It was found that while assessing the range of movements, ulnar was 25 degrees, radial was 15.60 , pronation was 70.75 degrees, supination was 77.42 degrees, palmar flexion was 60.15 degrees and dorsal was 60.45 degrees.

Table 4: Result comparison

\begin{tabular}{|c|c|c|c|c|}
\hline Series & Flexion & Extension & Pronation & Supination \\
\hline Kavin khatri et al. (2016) ${ }^{[13]}$ & 80 & 77 & 78 & 76 \\
\hline Paritosh Gogna et al. (2013) ${ }^{[11]}$ & 54 & 58 & 80 & 84 \\
\hline Ahyan kilc et al. (2009) ${ }^{[14]}$ & 75.1 & 75.2 & 77.8 & 78.3 \\
\hline Present Study & 60.15 & 60.45 & 70.75 & 77.43 \\
\hline
\end{tabular}

At the final analysis of the outcome of our study excellent results were noted in 15 cases $45.45 \%$, good results were noted in 11 cases $33.33 \%$, fair results were noted in 5 cases $15.15 \%$, poor results were noted in 2 cases $6.06 \%$. Murakami et al. ${ }^{[15]}$ reported $83 \%$ excellent and $17 \%$ good outcome in their series of 24 patients of unstable distal radius fractures fixed with volar locking plate. Kavin Khatri et al. ${ }^{[13]}$ (2016) stated at the end of 6 weeks following treatment found that to Gartland and Werley scores excellent results in $65.2 \%$ cases and good results in $35 \%$ cases. Figl et al. ${ }^{[16]}$ reported excellent results in $37.5 \%$ of patients, good results in $57 \%$, and fair results in 5.5\%. Paritosh Gogna et al. (2013) ${ }^{[11]}$ had excellent results in $79 \%(n=26)$, good in $18 \%(n=6)$, and fair in $3 \%(\mathrm{n}=1)$ patients. In study conducted by Ahyan kilc et at (2009) [14], out of 27 patients, 12 (44.4\%) patient having excellent result and $12(44.4 \%)$ patient achieved good result and $3(11.1 \%)$ patient achieved fair result.

\section{Conclusions}

Fracture of distal end of radius is one of the commonest fractures. This fracture is more common in males $(87.8 \%)$ with predominance on right side. Road traffic accident is still the common mode of injury than fall. On follow up excellent functional outcome found in $45.45 . \%$ cases with $81.82 \%$ patients achieved good grip strength.

Limitations: The sample size was small in study and follow up period was insufficient. As of many patients was managed by cast and $\mathrm{k}$ wire only due to patient non-compliance to give proper follow up and unwillingness for surgery. Thus, further prospective study with large population and longer follow up time were required to evaluate the clinical outcome.

\section{References}

1. Meena S, Sharma P, Sambharia AK, Dawar A. Fractures of distal radius: an overview. Journal of family medicine and primary care. $2014 ; 3(4): 325$.

2. Leung F, Tu YK, Chew WY et al. Comparison of external and percutaneous pin fixation with plate fixation for intra-articular distal radial fractures. A randomized study. J Bone Joint Surg Am. 2008; 90(1):16-22

3. Makhni EC, Ewald TJ, Kelly S, Day CS. Effect of Patient Age on the Radiographic Outcomes of Distal Radius Fractures Subject to Nonoperative Treatment. J Hand Surg. 2008; 33A:1301-8.

4. Ellis J. Smith's and Barton's fractures. A method of 
treatment. J Bone Joint Surg Br. 1965; 47(4):724-727.

5. Von Recum J, Matschke S, Jupiter JB et al. Characteristics of two different locking compression plates in the volar fixation of complex articular distal radius fractures. Bone Joint Res. 2012; 1(6):111-117.

6. Knirk JL, Jupiter JB, Intra-articular fractures of distal radius in young adults. J Bone Joint 547-549.

7. Miranda MA. Locking plate technology and its role in osteoporotic fractures. Injury. 2007; 38(3):35-39.

8. Osada D, Kamei S, Masuzaki K, Takai M, Kameda M, Tamai K. Prospective study of distal radius fractures treated with a volar locking plate system. The Journal of hand surgery. 2008; 33(5):691-700.

9. Weninger P, Dall'Ara E, Drobetz H, Nemec W, Figl M, Redl $\mathrm{H}$ et al. Multidirectional volar fixed-angle plating using cancellous locking screws for distal radius fractures-evaluation of three screw configurations in an extra-articular fracture model. Wiener Klinische Wochenschrift. 2011; 123(1-2):4-10.

10. Orbay J, Badia A, Khoury RK, Gonzalez E, Indriago I. Volar fixed-angle fixation of distal radius fractures: the DVR plate. Techniques in hand \& upper extremity surgery. 2004; 8(3):142-148.

11. Gogna P, Selhi HS, Singla R, Devgan A, Magu NK, Mahindra $\mathrm{P}$ et al. Dorsally comminuted fractures of the distal end of the radius: Osteosynthesis with Volar Fixed Angle Locking Plates. ISRN orthopedics. 2013.

12. Khan SM, Saxena NK, Singhania SK, Gudhe M, Nikose $\mathrm{S}$, Arora $\mathrm{M}$ et al. Volar plating in distal end radius fractures and its clinical and radiological outcome as compared to other methods of treatment. Journal of Orthopaedics and Allied Sciences. 2016; 4(1):40.

13. Khatri K, Sharma V, Farooque K, Tiwari V. Surgical treatment of unstable distal radius fractures with a volar variable-angle locking plate: clinical and radiological outcomes. Archives of trauma research. 2016; 5(2).

14. Kilic A, Kabukcuoglu Y, Ozkaya U, Gul M, Sokucu S, Ozdogan U. Volar locking plate fixation of unstable distal radius fractures, Acta Orthop Traumatol Turc 2009; 43(4):303-308.

15. Murakami K, Abe Y, Takahashi K. Surgical treatment of unstable distal radius fractures with volar locking plates. Journal of Orthopaedic Science. 2007; 12(2):134-40.

16. Figl M, Weninger P, Liska M, Hofbauer M, Leixnering M. Volar fixed angle plate osteosynthesis of unstable distal radius fractures: 12 months results. Arch Orthop Trauma Surg. 2009; 129(5):661-669. 